\title{
Dietary fiber: An ingredient against obesity
}

\author{
Marisol Cruz-Requena', Cristóbal Noé Aguilar-González', Lilia Arely Prado-Barragan², \\ María das Graças Carneiro-da Cunha ${ }^{3}$, Maria Tereza dos Santos Correia ${ }^{3}$, \\ Juan Carlos Contreras-Esquivel'1, Raul Rodríguez-Herrera ${ }^{1 *}$
}

${ }^{1}$ Departament of Food Research, School of Chemistry, Universidad Autónoma de Coahuila, Saltillo, Coahuila, México, ${ }^{2 B}$ Biotechnology Department, Universidad Autonoma Metropolitana, Ciudad de México, Distrito Federal, México, ${ }^{3}$ Biochemistry Department, Universidade Federal de Pernambuco (UFPE), Recife, Pernambuco, Brazil

\section{A B S T R A C T}

Nowdays, obesity is considered a health problem worldwide which predisposes to development of various metabolic diseases such as type 2 diabetes, cardiovascular disease and cancer among others, as well as, psychological disorders as depression. This condition has been increased through the time because of changes in lifestyle and modification in feeding type. This review provides an update of recent studies about obesity consequences on health and how a healthy diet, including dietary fiber, can helps to keep a healthy body weight and avoiding several diseases related to this condition. Several studies have reported that a healthy and balanced diet helps to control human weight, added to this, a diet rich in dietary fiber (from natural sources or produced biotechnologically) helps to keep a body weight regulation, control of lipid and triglycerides levels because of its chemical, physical and biochemical features. One of the these features is hormonal regulation through dietary fiber consumption, in as much as that several appetite and satiety hormones in the organism are activated in presence of dietary fiber and provides an effect of satiety which causes a decrease in food consumption. Therefore, consumption of dietary fiber of several sources could be an alternative for controlling obesity-related diseases and preventing this condition.

Keywords: Body weight regulation; Cancer; Diabetes; Ghrelin; Glucagón like peptide-1

\section{INTRODUCTION}

Obesity is defined, in general terms, as physical manifestation of anormal fat accumulation that alters health and increases mortality. Nowdays, this condition is recognized as a prevalent metabolic disease that has reached epidemic proportions in both developed and developing countries, affecting adults, adolescents and children (Tsigos et al., 2008). According to the World Health Organization (WHO, 2016), in 2014, $39 \%$ of adults aged $18+$ were overweight (BMI $\geq 25 \mathrm{~kg} / \mathrm{m} 2)(39 \%$ men and $40 \%$ of women). In $2014,39 \%$ of adults aged $18+$ were overweight (BMI $\geq$ $25 \mathrm{~kg} / \mathrm{m} 2$ ) (39\% of men and $40 \%$ of women) and $13 \%$ were obese (BMI $\geq 30 \mathrm{~kg} / \mathrm{m} 2) \quad(11 \%$ of men and $15 \%$ of women). Thus, nearly 2 billion adults worldwide are overweight and, of these, more than half a billion are obese.

There are factors that have influenced on the increase of obesity around the world and time, demographics changes since mid-twentieth century where abouth $80 \%$ of the population live in urban ares, which has favored a change in life style, incluiding eating habits exchanging fresh fruits and vegetables for foods with high levels of cholesterol, saturated fats, starch, sugars, sodium, among others, increasing nutrition related chronic diseases such as metabolic syndrome, obesity and diabetes (Fausto-Guerra et al., 2006), and most of these elections are an unconscious behavior, a voluntary food consumption made by the population.

On the other side, evidence suggests that balance in food intake and energy consumption is controlled by a biological system. There are chemical molecules with functional properties involved in the equilibrium of energy consumption, thus reducing risk of obesity and among these compounds are dietary fibers (Howarth et al., 2001). Galisteo and Zarzuelo (2008) reported that several studies in humans and experimental models demonstrate efficiency of dietary fiber on regulation of body weight, food consumption, glucose homeostasis, insulin quality and risk factors for cardiovascular disease such as lipids profile, hypertension and systemic inflammatory markers. For this

\footnotetext{
*Corresponding author:

Rodríguez-Herrera Raul, Departament of Food Research, School of Chemistry, Universidad Autónoma de Coahuila, Saltillo, Coahuila, México. Tel.: +52 (844) 416-1238 and 416-9213. Fax +52 (844) 439-0511. E-mail: rrh961@hotmail.com
} 
reasons, it is important to emphasize the effect of dietary fiber consumption on body weight control and reduction of metabolic diseases incidence. The goals of this review are to describe the health obesity consequences due to type of feeding as well as the body hormonal regulation through several appetite hormones as leptin, glucagon-like peptide (GLP-1) and ghrelin. Also, some of the chemical and functional features of dietary fiber will be described and some evidences that suggest how a diet rich in these food components can help to reduce and maintain a healthy weight. We know the complexity of obesity and that is a subject that required a wide analysis, so in this review we just give a definition and some aspects which are related to this condition.

\section{Obesity}

Obesity is a complex physiologic state that is associated with several metabolic changes as hyperinsulinemia, hyperglycemia, hyperlipidemia, altered adiopokine profile (higher leptin and lower adiponectin) and generalized inflammation, which increase the risk factor for insulin resistance, type 2 diabetes, heart disease and many other chronic diseases. Due to the increase of this condition around de world, has become in an epidemic (Khandekar et al., 2011; Zimmet and Thomas, 2003). There are many factors implicated on obesity incidence such as genetic, physiological, environmental, social, economic and political (Wright and Aronne, 2012). The problem starts when there is a positive balance between energy consumption, mainly stored as triglycerides (food intake, energy consumption, basal metabolism and biochemical processes) and food intake. Excess of stored energy is mainly accumulated in form of adipose tissue as triglycerides. When adipose tissue function is compromised during obesity, excess of fat which is stored in adipose tissue, liver and other organs predisposes individuals to development of metabolic changes which increase disease risk (Spiegelman and Flier, 2001).

\section{Obesity and others health consequences}

Due to the physiological changes derived from obesity, this condition has been related to other health consequences, moreover of diabetes and hypertension which are the most common and knowns. One of these health consequences is depression, psychological condition consequence of obesity which has been lees studied and less well understood until now, in comparation with physiological consequences which have been widely studied (Markowitz et al., 2008). But several researchers mentioned that obesity may increase depression risk; and depression may promote obesity (Markowitz et al., 2008; Simon et al., 2006). According to WHO (2012), depression is a common mental disorder, characterized by sadness, loss of interest or pleasure, feelings of guilt or low self-worth, disturbed sleep or appetite, feelings of tiredness, and poor concentration.

However, there is a controversy among researchers about relationship of obesity and depression. Askari et al. (2013) studied the relationship between obesity and depression and concluded that there is not relationship among these health disorders. On the other side, several studies confirm that there is a moderate relationship between specifically abdominal obesity and waist circumference and depressive symptoms in the general population (Xu et al., 2011; Zhao et al., 2011). Lupino et al. (2010) performed a meta-analysis examining the longitudinal bidirectional relation between depression and overweight (body mass index 25-29.99) or obesity (body mass index $\geq 30$ ) and founded that there are an association between depression and obesity stronger than the association between depression and overweight. Likewise, there is a difference in the form of affectation between genders since Mannan et al. (2016) concluded that the strength of the association is greater for the direction leading from depression to obesity and this link was more pronounced for young and middle aged women. However, there are several factors which may influence these relationships since as Markowitz et al. (2008) mentioned in their study that proposed mechanisms by which obesity confers risk for depression unidirectional include the behavioral factor of dieting and the social factor of stigma faced by the obese and there may be a causal pathway from depression to obesity that operates through behavioral mechanisms of poor adherence and lack of exercise, cognitive mechanisms such as negative thoughts, and social mechanisms such as reduced support. The link between obesity and depression may be studied profoundly, being that both factors are an unnatural human condition which could be avoided, especially when one derived from other.

Due that obesity modify the natural condition of the organism, there are a several physiological changes which alter the body functionality, leading to health consequences. Whithin the health consequences of obesity we can found different type of cancer, which is currently the leading cause of death in developed countries and second in developing countries (Jemal et al., 2011; Arnold et al., 2016). There is evidence that support a relationship between obesity and some type of cancer. Several metanalysis has showed the relationship between breast cancer in postmenopausal and obese women (Healy et al., 2010; Aguilar-Cordero et al., 2012), likewise, has been correlated obesity with a cumulative incidence of distant metastases in ER-/HER2 positive breast cancer (Mazzarella et al., 2012). According to the World Cancer Research Fund International (WCRF International, 2014) colorectal cancer is the third most common cancer throught the world, with nearly 1.4 million new cases diagnosed in 2012 and has been suggested to have 
a certain relationship with obesity in some epidemiological studies which relationed abdominal adiposity with an elevated risk of colon cancer in man (GiovannuccI et al., 1995; Dai et al., 2007; Ramadas et al., 2009; Hano García et al., 2011), and ir related to a advanced colorectal adenoma formation (Chung et al., 2006).

On the other hand, studies have demonstrated that almost half of all kidney tumors are linked to obesity (i.e., body mass index $[\mathrm{BMT}]>30 \mathrm{~kg} / \mathrm{m}^{2}$ ), and renal cancer risk is $20 \%$ to $35 \%$ higher for every $5 \mathrm{~kg} / \mathrm{m} 2$ of higher BMI (Bergström et al., 2001; Renehan et al., 2008; Mathew et al., 2009). Approximately $90 \%$ of all kidney cancers are renal cell carcinomas (RCC) and have been well established the risk factors as smoking, overweight and obesity, and germline mutations in specific genes. The mechanisms by which obesity may increase RCC risk are not well understood. An increased exposure to the sex steroids oestrogen and androgen is one possible mechanism (Lecumberri et al., 2007).

Pancreatic cancer is another type of cancer that has been associated to obesity. Studies have supported this association through meta-analysis, where has been observed that an elevated body mass indice (BMI) of 25 and 35 increased pancreatic cancer risk, both men and women (Larsson et al., 2007). In like manner, Silverman et al. (1998) studied the relation between the diet and their influence on development of pancreatic cancer in black and white persons as well as between men and women and they founded that the energy balance may play an important role in pancreatic carcinogenesis regardless of origin or sex. Others conditions associated to pancreatic cancer development and their relationship to obesity are the hyperinulinemia and possibly hyperestrongenism secondary to a metabolic syndrome, independently from diabetes status and secondary to excess body fat (Preziosi et al., 2014).

Amongst all cancers, the one that is most strongly enhanced by obesity is hepatocellular carcinoma cancer (HCC). Several meta-analyses have revealed the association between the excess body weigth increased risk of liver cancer among overweight and obese persons (Larsson and Wolk, 2007, Chen et al., 2012). The mechanisms that are liked to development of this type of cancer are the accumulation of lipids in the liver which promote activation of an inflammatory response through the activation of cytokines by adipokines as leptin, adiponectin and IL1. Besides, lipid accumulation increases demand on the endoplasmic reticulm increased the production of reactive oxygen species (ROS), which stimulate inflammatory singnalind and induce oxidative damage as strand breaks and nucleotide modifications (Toffanin et al., 2010; Shimizu et al., 2012; Sun and Karin, 2012). On the other side, there are evidence that support the association between obesity and HCC development in patients without markers of hepatitis virus $B$ virus and hepatitis $C$ virus infection as well as withouth drinking or smoking habits, which are others factors involved in HCC development (Polesel et al., 2009). Due to the cancer has become in one of the most mortal diseases around the world, is necessary to establish the bases of the relationship between development of cancer and and obesity, being that occurrence of this type of diseases are preventable in most of the cases keeping a healthy weight.

\section{Body weight regulation}

There are at least three factors which influence body weight regulation: the first factor is individual diet, being that this affects energetic equilibrium; the second factor is treatment and prevention of obesity. Finally, the last factor is the related signals with hunger and appetite which are of physiological, cognitive and environmental origin (Bell and Rolls, 2001). Origin of physiological signals is the hormone system, which is a complex, including peripheral and central factor. Two hormones that play an important role in the regulation of food intake and body weight are leptin and ghrelin (Klok et al., 2007). Ghrelin is an endogenous ligand for the receptor of growth hormone secretagogue (GHSR) and which is produced mainly by the stomach (Disse et al., 2012). Evidence suggests that ghrelin may play a role in signaling and reversing states of energy insufficiency (Zigman et al., 2005). Besides, ghrelin is a physiological mediator of feeding, and probably has a function on growth regulation by stimulating feeding and releasing of growth hormone (Müller et al., 2013).

Furthermore, leptin is a mediator of long-term regulation of energy balance, suppressing food intake and thus inducing weight loss (Klok et al., 2007; Nakasato et al., 2000). Likewise, this hormone is derived from adipose tissue and is produced in proportion to the fat storage in part of a negative feedback loop that maintains a set point for body fat stores (Considine et al., 1996).

Moreover, the glucagon-like peptide (GLP-1) is an incretin hormone involved in glucose homeostasis. In particular, the efficiency of this hormone has been showed on decreasing of glucose concentration in blood, improving secretion and insulin resistance in addition to preserving the function of pancreatic $\beta$ cells, inhibiting of glucagon secretion, and gastrointestinal motility (Holst, 2007). GLP-1 is secreted from enteroendocrine L cells, which are located in the distal ileum and colon (Drucker, 1998), this hormone acts through a specific $G$ protein coupled to a receptor to stimulate secretion of glucose-dependent insulin (Weir, et al., 1989). A decrease in GLP-1 secretion may contribute to development of obesity, and an exaggerated secretion of 
it may cause postprandial reactive hypoglycemia (Drucker, 1998). Stabilization of glucosa and cholesterol levels may be aided by intake of dietary fibers.

\section{Feeding quality and weight control}

Environment influences obesity development since individual lifestyle behavior such as what and how much a person eats, as well as his or her level of physical activity (Wellman, and Friedberg, 2002). Besides, obesity is related to food choices, which is influenced for several factors such as individual preferences, availability, situation, sensory hedonic likes and so on (Mela, 2001). Different studies show a relationship between quality, type and amount of food and obesity development as well as the healthy weight control. Anderson et al. (2011) examined frequency and characteristics of fast-food consumption among adults and obesity prevalence and they founded that obesity prevalence increased consistently with frequenting fast-food restaurants. Likewise, Swinburn et al. (2004) mentioned that the principal factors to increase obesity are the feeding habits as energy dense foods (principally related their fat content but sometimes their carbohydrate content), high energy drinks and large portion sizes.

Body weight loss and prevention of body weight (re) gain can thus be achieved by reducing energy intake or bioavailability, increasing energy expenditure and/or otherwise reducing storage as fat (Kovacs and Mela, 2006). Champagne et al. (2011) studied the impact of changes in dietary consumption on weight loss and maintenance and they concluded that an increment of fruits, vegetables and low-fat dairy may help achieve weight loss and maintenance. Therefore, one way to reducing energy density of meals and overall diets is by substituting relatively energy-density foods in the diet for less energy dense foods such as fruits and vegetables (Rodríguez et al., 2005; Conceição de Oliveira et al., 2005; Alina et al., 2009), whole grains (Melanson., 2006), nuts (Sabaté, 2003) and beans (Udani and Singh, 2007) which provide essential vitamins and minerals, fiber, and other substances that are important for good health and help to maintain a healthy weight. Thus, is not just reduce the amount of food or calories consumed, is necessary to choose the right food that provides necessary nutrients to reach an optimal healthy weight.

One of the foods which provide an option to handle the body weight is food rich in dietary fiber. A diet rich in dietary fiber gives a healthy and balanced diet in as much as it has been demonstrated that may influence body-weight regulation by physiological mechanisms involving intrinsic, hormonal and colonic effects (Pereira and Ludwig, 2001). Slavin (2004) mentions that addition of functional fiber to weight-loss diets should also be considered as a tool to improve success. The success of weight control trough a dietary fiber intake is that promotes satiation and prolongs satiety (Burton-Freeman, 2000).

\section{Dietary fiber}

There are several definitions of dietary fiber which differ in complexity, taking in account chemical composition and physiological effects. Codex Alimentarius Commission define dietary fiber as carbohydrate polymers with a degree of polimerization (DP) not lower than 3, which are neither digested nor absorbed in the small intestine and can be found naturally in food consumed or have been obtained from food raw material by physical, enzymatical or chemical ways and gives to organism many health benefits (FAO, 2006). On the other side, AACC (2001) define dietary fiber as edible part of plants or carbon hydrates analogues that are resistant to digestion and absorption in the small intestine with complete or partial fermentation in the large intestine. Dietary fiber includes polysaccharides, oligosaccharides, lignin and associated plant substances.

With respect to their solubility in water, dietary fiber can be classified as soluble an insoluble, while their technological functionality and nutritional effects of dietary fibers are determined by its physicochemical properties. Soluble fibers are mainly composed of non-cellulosic polysaccharides (pectin, gums, mucilage and hemicelluloses) and forms dispersion in water, thereby facilitates formation of viscous gels into the gastrointestinal tract, which slows gastric emptiness. These fermentable soluble fibers are associated with metabolism of carbohydrates and lipids and it is found in large amounts in fruits and seaweed. Furthermore, insoluble fibers increase fecal volume up to 20 times because of its water retention capacity and are mainly composed by cellulose, hemicellulose and lignin. This type of fiber is found mainly in vegetables, grains, legumes and fruits (Lecumberri et al., 2007; Matos-Chamorro and Chambilla-Mamani, 2010) and help to reduce concentration and contact time of potential carcinogens with the intestinal mucosa (Kim, 2000). In addition to the different sources of fibers (fruits, plants, vegetables among others), there are by-products of these sources which have good physicochemical properties like onion by-products, and bagasse which has a good balance between soluble and insoluble fraction (Benitez et al., 2012).

According to vegetal source and growing conditions (cropping, genus or specie) dietary fiber may vary in chemical composition and functional properties (Schneeman, 1986). Salehifar and Fadaei (2011) extracted dietary fibers from rice bran using an enzyme and a chemical method and found that enzymatic method offered better performance than the chemical method 
$(33.97 \%$ vs. $67.53 \%)$ and the drawn fibers had higher water and fat holding capacity. Other factor influencing fibers functionality is degree of polymerization. Kruger et al. (2003) studied effect of fructooligosaccharides with different degree of polymerization and found that these have different effects on absorption and retention of calcium, bone density and collagen excretion in rats.

\section{Beneficial health effects of dietary fiber}

The role of dietary fibre in the body is physiological one and not chemical one, due their functional properties and their effect on the gastrointestinal tract (GI) which improves the gut motility, but also on chemical and bacteriological changes that occur in the intestine (Brownlee et al., 2006; Burkitt et al., 1974). There are two ways in which dietary fiber favors the gut motility; first is their capacity to hold water which contribute to fecal bulk, increamenting stool mass and therefore intestinal luminal bulk due to water retention of dietary fiber increasing persitalsis (Dello Staffolo et al., 2012). On the other hand, the fermentation of dietary fibers in the large intestine by microbiota produces short chain fatty acids (SCFA) as butyrate, propionate and acetate. Especifically, butirate has been associated to gut motility through their relathionship with the enteric system nervous (ENS), which controls the gut motility (Campbell, 2015). In a research made by Soret et al. (2010) where studied the neurons relationed with the ENS, they observed that butyrate increased the proportion of cholinergic neurons in rats and they demostred that exist an increase in the proportion of ChAT-IR neurons, associated with an increased in ChAT mRNA expression, suggesting a regulation of ChAT gene transcription by butirate.

Then, dietary fiber may contribute to decrease occurrence of certain chronic diseases. Functional properties that have been attributed to dietary fibers are diverse and among them are: protection against enteric infections, activation of bowel function, aid in nutrients digestion and absorption, stimulation of immune response (Kolida et al., 2002), regulation of cholesterol levels (Delzenne and Kok, 2001), positive effect on calcium absorption and bone mineralization (Franck, 2006), reduced serum concentrations of triacylglycerol and phospholipids (Roberfroid, 2000) and intestinal immunomodulation (Fukasawa et al., 2007). Specifically, insoluble fiber has potential hypoglycemic effects: adsorb glucose, retard glucose diffusion, postpone release of glucose from starch, and inhibit $\alpha$-amylase activity to different extents (Chau et al., 2004).

Dietary fiber is not considered an essential nutrient, but plays an important role on energy consumption modulation, which suggests a decreased risk of developing obesity (Friedman, 2009), this is can due a that different types of fibre affect subjective appetite, acute energy intake, long-term energy intake and body weight differently (Wanders et al., 2011). In addition, a high intake of dietary fiber, particularly soluble type, improves glycemic control, decreases hyperinsulinemia and lowers plasma lipid concentrations in patients with diabetes mellitus type 2 (Cani et al., 2008).

\section{Dietary fiber and obesity}

At the present time, the growing epidemic of obesity and type 2 diabetes obliges the scientific community to develop new therapies to combat these metabolic diseases. Excessive energy consumption as well as reducing the physical activity is two classical factors associated with development of this condition. Among the most common causes to develop these diseases is diet rich in fat, which generates metabolic disorders (Cani et al., 2008).

There are several studies where the presence of dietary fiber as part of the diet helps to control and reduce the obesity. Isken et al., (2008) studied the protector effect of a guar gum soluble fiber against a cereal insoluble fiber in obese rats and observed that after 45 weeks of feeding rats with fibers, their weight was increased and insulin resistant markers. Their results also showed that mice fed with insoluble cereal fiber resulted in weight gain, improved insulin sensitivity and an increase in fatty acid oxidation. Similarly, soluble fiber consumption increase short chain fatty acids (SCFA) production which significantly contributes to energy absorption, but may adversely affect energy homeostasis at long term. Several studies have proven effectiveness of dietary fiber intake in mice to control obesity and its consequences. It has been suggested that high fiber foods may increase gastric distension and promote satiety (Stanley et al., 1986). The gel-forming properties and viscosity of soluble fiber are involved in reduction of macronutrients absorption, slow gastric emptiness, reduction of postprandial glucose response and total cholesterol and low density lipoprotein (LDL). Fiber fermentation naturally takes place in the colon and subsequent SCFA production may also be attributable to soluble fiber consumption, while effects on inflammatory markers and moderated loss of weight is due to low density food and increase satiety and has been attributed to use of both soluble and insoluble dietary fiber intake (Friedman, 2009; King et al., 2007; Weickert and Pfeiffer, 2008). Dietary fiber such as gums, pectins, alginates, $\beta$-glucans, induces viscous swelling when mixed with fluids. Degree of swelling depends on different factors such as structure, chemical composition, concentration and molecular weight of dietary fiber (Dikeman and Fahey, 2006). 
Urías-Silvas et al. (2008) evaluated the potential of inulin fructan type from Agave tequilana to modulate metabolism of lipids and glucose and secretion of GLP-1 in mice and found that weight gain, glucose levels and serum cholesterol in mice fed with diets containing fructans, was lower than those fed with standard diet, suggesting positive effect of inulin on metabolism of sugars, weight gain and body fat accumulation. Other studies showed how dietary fiber of two different sources as Hibiscus sabdariffa and agave fructans of Agave tequilana can induce a positive effect as reduction in body weight, adiposity, plasma total cholesterol and glucose (Moyano et al., 2016). Wang et al. (2007) suggested that dietary fiber consumption decreases leptin secretion in a high-fat diet and decreases gastric ghrelin expression and also increases GLP-1 concentration. In other studies, where it was examined body weight, fat, hormones and expression of genes related to lipid and glucose metabolism in rats with diets with high fiber and protein content, it was noted that weight gain of mice was lower in those with high-fiber diets, likewise levels of glucose in plasma were reduced. Furthermore, it was found that GLP-1 levels were higher in mice fed with high-fiber diet, concluding that a high fiber diet provides protection when consumed in large amounts. Rendón-Huerta et al. (2012) studied the effect of Cichorium intybus L. Asteraceae, Helianthus tuberosus L. Asteraseae and Agave angustifolia ssp. Tequilana Haw, Agavaceace fructans on weight, blood metabolites (glucose, cholesterol and triglycerides) and fecal bacteria in rats with normal weight, obese, non-diabetic and diabetic. Results showed that in the group of rats with normal weight (diabetic and non-diabetic), concentrations of blood glucose and cholesterol in diabetic rats were lower in rats with diets supplemented with fructans. Furthermore, in the obese rat group (diabetic and non-diabetic), final weight was lower in those with diet supplemented with fructans, unlike normal diets without fructans, blood concentration of HDL, glucose and triglyceride levels in diabetic rats was higher than in non-diabetic, whereas blood concentration of HDL was lower in the diabetic rats. They concluded that fructans can modulate parameters altered in obesity and body weight such as diabetes, hyperglycemia and hypercholesterolemia. In the same way, cellulose has been tested as functional agent against absorption and excretion of lipids and cholesterol. Chau et al. (2008), tested in hamsters in vivo a commercial plant cellulose and a biocellulose synthesized from Acetobacter xylinum and observed that serum concentrations of triglyceride, cholesterol and LDL cholesterol and lipid and total cholesterol in liver were lower in diets containing both types of cellulose in comparison with diets without cellulose, and biocellulose showed better functionality. Grover et al., (2011) studied the effect on consumption of PolyGlycopleX ${ }^{\circledR}[(\alpha-\mathrm{D}$-glucurono- $\alpha-\mathrm{D}$-manno- $\beta$ $\mathrm{D}$-manno- $\beta$-D-gluco), ( $\alpha$-L-gulurono- $\beta$-D mannurono), $\beta$-D-gluco- $\beta$-D-mannan $\left.\left(\mathrm{PGX}{ }^{\circledR}\right)\right]$ by Zucker diabetic rats against inert cellulose fiber or water-soluble, prebiotic fiber and found that no digestible polyGlycopleX ${ }^{\circledR}$ reduces food intake but not reduced body weight. This type of fiber improves glycemic control in rats and appears to act as an insulin secretagogue, as polyGlycopleX $₫$ increases in blood GLP-1 accompanied by increased secretion of ghrelin, which could may have prevented weight loss secondary to reduced food intake because of its multiple effects on energy homeostasis.

\section{CONCLUSIONS}

A diet rich in dietary fiber is an alternative to promote a healthy weight, in as much as is a positive ripple effect because of its effects through all gastrointestinal tract, first with releasing and regulation of satiety hormones, regulating metabolite levels as HDL, LDL, triglycerides. Because its chemical interactions, dietary fiber promotes fast evacuation and is a carbon source to several lactic bacteria, which fermente dietary fiber producing several beneficial metabolites such as short chain fatty acids. Consumption of dietary fiber may be a partner in prevention and treatment of body weight control and obesity, like all the secondary diseases derived from this condition.

\section{ACKNOWLEDGMENTS}

We want to thanks to the Mexican Council of Science and Technology (CONACYT) and the Universidad Autonoma de Coahuila for the support to this project.

\section{Authors' contribution}

Marisol Cruz Requena was the main researcher and author of this manuscript. Cristóbal Aguilar, Lilia Prado, Juan Contreras, María das Graças Carneiro-da Cunha, Maria Tereza Correia and Raúl Rodríguez contributed significantly to the research effort and writing, editing specific sections and approved the final version of the manuscript.

\section{REFERENCES}

AACC. 2001. Report of the dietary fiber definition committee to the board of directors of the American Association of Cereal Chemists. Cereal Food World. 46: 112-126.

Aguilar-Cordero, M. J., M. N. Neri-Sánchez, C. A. Padilla-López, M. L. Pimentel Ramírez, A. Carcía-Rillo and N. Mur-Villar. 2012. Overweight/obesity in women and its implication in breast cancer; Age of diagnosis. Nutr. Hosp. 27: 1643-1647.

Alina, S., O. Hels and I. Tetens. 2009. The potential association between fruit intake and body weight $-\mathrm{A}$ review. Obes. Rev. 10: 639-647.

Anderson, B., A. P. Rafferty, S. Lyon-Callo, C. Fussman and G. Imes. 2011. Fast-food consumption and obesity among Michigan adults. Prev. Chronic Dis. 8: A71. 
Arnold, M., M. Leitzmann, H. Freisling, F. Bray, I. Romieu, A. Renehan and I. Seorjomataram. 2016. Obesity and cancer: An update of the global impact. Cancer Epidemiol. 41: 8-15.

Askari, J., A. Hassanbeigi, H. Mozaffar Khosravi, M. Malek, D. Hassanbeigi, Z. Pourmovahed and M. Alagheband. 2013. The relationship between obesity and depression. Proc. Soc. Behav. Sci. 84: 796-800.

Bell, A. and B. J. Rolls. 2001. Regulación de la ingesta de energía: Factores que contribuyen a la obesidad. In: B. A. Bowman (Ed.), Conocimientos Actuales Sobre Nutrición. Organización Panamericana de la Salud, Washington, D. C., p. 34.

Benitez, V., E. Molla, M. A. Martín-Cabrejas, F. J. López-Andréu and R. M. Esteban. 2012. Onion (Allium cepa L.) By-products as source of dietary fiber: Physicochemical properties and effect on serum lipid levels in high-fat rats. Eur. Food Res. Technol. 234: 617-626.

Bergström, A., C. C. Hsieh, P. Lindbland, C. M. Lu, N. R. Cook and A. Wolk. 2001. Obesity and renal cell cancer - A quantitative review. Br. J. Cancer. 85: 984-990.

Brownlee, I. A., P. W. Dettmar, V. Strugala and J. P. Person. 2006. The interaction of dietary fibres with the colon. Curr. Nutr. Food Sci. 2: 243-264.

Burkitt, D. P., A. R. P. Walker and N. S. Painter. 1974. Dietary fiber and disease. JAMA. 229: 1068-1074.

Burton-Freeman, B. 2000. Dietary fiber and energy regulation. J. Nutr. 130: 272S-275S.

Campbell, I. 2015. Gut motility and its control. Anaesth. Intensive Care. Med. 16: 40-42.

Cani, P. D., N. M. Delzenne, J. Amar and R. Burcelin. 2008. Role of gut microflora in the development of obesity and insulin resistance following high-fat diet feeding. Pathol. Biol. 56: 305-309.

Champagne, C. M., S. T. Broyles, L. D. Moran, K. C. Cash, E. J. Levy, P. H. Lin, B. C. Batch, L. F. Lien and K. L. Funk. 2011. Dietary intakes associated with successful weight loss and maintenance during the weight loss maintenance trial. J. Am. Diet. Assoc. 111: 1826-1835.

Chau, C. F., C. H. Chen and C. Y. Lin. 2004. Insoluble fiber-rich fractions derived from Averrhoa carambola: Hypoglycemic effects determined by in vitro methods. LWT-Food Sci. Technol. 37: 331-335.

Chau, C. F., P. Yang, C. M. Yu and G. C. Yen. 2008. Investigation on the lipid - And cholesterol-lowering abilities of biocellulose. J. Agric. Food Chem. 56: 2291-2295.

Chen, Y., X. Wang, J. Wang, Z. Yan and J. Luo. 2012. Excess body weight and the risk of primary liver cancer: An updated metaanalysis of prospective studies. Eur. J. Cancer. 48: 2137-2145.

Chung, Y. W., D. S. Han, Y. K. Park, B. K. Son, C. H. Paik, H. L. Lee, Y. C. Jeon and J. H. Sohn. 2006. Association of obesiy, serum glucose and lipids with the risk of advanced colonrectal adenoma and cancer: A case-control study in Korea. Dig. Liver Dis. 38: 668-672.

Conceição de Oliveira, M., R. Sichieri and R. Venturium Mozzer. 2008. A low-energy-dense diet adding fruit reduces weight and energy intake in women. Appetite. 51: 291-295.

Considine, R. V., M. K. Sinha, M. L. Heiman, A. Kriauciunas, T. W. Stephens, M. C. Nyce, J. P. Ohannesian, C. C. Marco, L. J. McKee and T. L. Bauer. 1996. Serum immunoreactive-leptin concentrations in normal-weight and obese humans. N. Engl. J. Med. 334: 292-295.

Dai, Z., Y. C. Xu and L. Niu. 2007. Obesity and colorectal cancer risk: A meta-analysis of cohort studies. World J. Gastroenterol. 13: 4199-4206.

Dello Staffolo, M., A. E. Bevilacqua, M. S. Rodríguez and
L. Albertengo. 2012. Dietary fiber and availability of nutrients: A case study on yoghurt as a food model. The Complex World of Polysaccharides, In: D. N. Karunaratne (Ed.). Available from: http://www.informahealthcare.com/userimages/ ContentEditor/1408369350540/IJF_IFAs_Ithenticate.pdf. [Last accesed on 2015 May 27].

Delzenne, N. M. and N. Kok. 2001. Effects of fructans-type prebiotics on lipid metabolism. Am. J. Clin. Nutr. 73: 456S-458S.

Dikeman, C. L and G. C. Fahey. 2006. Viscosity as related to dietary fiber. A review. Crit. Rev. Food Sci. Nutr. 46: 649-663.

Disse, E., A. L. Bussier, C. Veyrat-Durebex, N. Deblon, P. T. Pfluger, M. H. Tschöp, M. Laville and F. Rohner-Jeanrenaud. 2010. Peripheral ghrelin enhances sweet taste food consumption and preference, regardless of its caloric content. Physiol. Behav. 101: $277-281$.

Drucker, D. J. 1998. Glucagon-likepeptide. Diabetes. 47: 159-169.

FAO/WHO (Food and Agricultural Organization/World Health Organization). 2006. Report of the $27^{\text {th }}$ Session of the Codex Committee on Nutrition and Foods for Special Dietary Uses. Bon, Germany, 21-25 November; 2005.

Fausto-Guerra, J., R. M. Valdez López, M. G. Aldrete Rodriguez and M. C. López Zermeño. 2006. Antecedentes históricos sociales de la obesidad en México. Invest. Salud. 8: 91-94.

Franck, A. 2006. Oligofructose-enriched inulin stimulates calcium absorption and bone mineralisation. Nutr. Bull. 31: 341-345.

Friedman, J. M. 2009. Causes and control of excess body fat. Nature. 459: 340-342.

Fukasawa, T., K. Murashima, I. Matsumoto, A. Hosono, H. Ohara and C. Nojiri. 2007. Identification of marker genes for intestinal immunomodulating effect of a fructooligosaccharide by DNA microarray analysis. J. Agric. Food Chem. 55: 3174-3179.

Galisteo-Duarte, J. and A. Zarzuelo. 2008. Effects of dietary fibers on disturbances clustered in the metabolic syndrome. J. Nutr. Biochem. 19: 71-84.

Giovannucci, E., A. Ascherio, E. B. Rimm, G. A. Colditz, M. J. Stampfer and W. C. Willett. 1995. Physical activity, obesity, and risk for colon cancer and adenoma in men. Ann. Int. Med. 122: 327-334.

Grover, G. J., L. Koetzner, J. Wicks, R. J. Gahler, M. R. Lyon, R. A. Reimer and S. Wood. 2011. Effects of the soluble fiber complex PoyGlycopleX® (PGX®) on glycemic control, insulin secretion and GLP-1 levels in Zucker diabetics rats. Life Sci. 88: 392-399.

Hano García, O. M., L. Wood Rodríguez and O. M. Villa Jiménez. 2011. Obesity and colorectal cancer risk. Rev. Cubana Invest. Bioméd. 30: 251-259.

Healy, L. A., A. M. Ryan, P. Carrol, D. Ennis, V. Crowley, T. Boyle, M. J. Kennedy, E. Connolly and J. V. Reynolds. 2010. Metabolic syndrome, central obesity and insulin resistance are associated with adverse pathological features in postmenopausal breast cancer. Clin. Oncol. 22: 281-288.

Holst, J. J. 2007. The physiology of glucagon-like peptide 1. Physiol. Rev. 87: 1409-1439.

Howarth, N. C., E. Saltzman and S. B. Robers. 2001. Dietary fiber and weight regulation. Nutr. Rev. 59: 163-169.

Isken, F., S. Klaus, M. Osterhoff, A. F. H. Pfeiffer and M. O. Weickert. 2008. Effects of long-term soluble vs. insoluble dietary fiber intake on high-fat diet-induced obesity in C57BL/6J mice. J. Nutr. Biochem. 21: 278-284.

Jemal, A., F. Bray, M. M. Center, J. Ferlay, E. Ward and D. Forman. 2011. Global cancer statistics. CA Cancer J. Clin. 61: 69-90.

Khandekar, M. J., P. Cohen and B. M. Spiegelman. 2011. Molecular 
mechanisms of cancer development in obesity. Nat. Rev. Cancer. 24: 886-895.

Kim, Y. I. 2000. AGA technical review: Impact of dietary fiber on colon cancer occurrence. Gastroenterology. 118: 1235-1257.

King, D. E., B. M. Egan, R. F. Woolson, A. G. Mainous $3^{\text {rd }}$, Y. Al-Solaiman and A. Jesri. 2007. Effect of a high-fiber diet vs a fiber-supplemented diet on C-reactive protein level. Arch. Int Med. 167: 502-506.

Klok, M. D., S. Jakobsdottir and M. L. Drent. 2007. The role of leptin and ghrelin in the regulation of food intake and body weight in humans: A review. Obes. Rev. 8: 21-34.

Kolida, S., K. Tuohy and G. R. Gibson. 2002. Prebiotic effects of inulin and oligofructose. Br. J. Nutr. 87: S193-S197.

Kovacs, E. M. R. and D. J. Mela. 2006. Metabolically active functional food ingredients for weight control. Obes. Rev. 7: 59-34.

Kruger, M. C., K. E. Brown, G. Collett, L. Layton and L. M. Schollum. 2003. The effect of fructooligosaccharides with various degrees of polymerization on calcium bioavailability in the growing rat. Exp. Biol. Med. 228: 683-688.

Larsson, S. C. and A. Wolk. 2007. Overweight, obesity and risk of liver cancer: A meta-analysis of cohort studies. Br. J. Cancer. 97: 1005-1008.

Larsson, S. C., N. Orsini and A. Wolk. 2007. Body mass index and pancreatic cancer risk: A meta-analysis of prospective studios. Int. J. Cancer. 120: 1993-1998.

Lecumberri, E., R. Mateos, M. Izquierdo-Pulido, P. Rupérez, L. Goya and L. Bravo. 2007. Dietary fiber composition, antioxidant capacity and physico-chemical properties of a fiber-rich product from cocoa (Theobroma cacao L.). Food Chem. 104: 948-954.

Lupino, F. S., L. M. de Wit, P. F. Bouvy, T. Stijnen, P. Cuijpers, B. W. J. Penninx and F. G. Zitman. 2010. Overweight, obesity, and depression a systematic review and meta-analysis of longitudinal studies. Arch. Gen. Psychiatry. 67: 220-229.

Mannan, M., A. Mamun, S. Doi and A. Clavarino. 2016. Is there a bidirectional relationship between depression and obesity among adult men and women? Systematic review and bias-adjusted meta analysis. Asian J. Psychiatry. 21: 51-66.

Markowitz, S., A. Michael, M. A. Friedman and S. A. Arent. 2008. Understanding the relation between obesity and depression: Causal mechanisms and implications for treatment. Clin. Psychol. Sci. Pract. 15: 1-20.

Mathew, A., P. S. George and G. Ildaphonse. 2009. Obesity and kidney cancer risk in women - A meta-analysis (1992-2008). Asian Pac. J. Cancer Prev. 10: 471-478.

Matos-Chamorro, A. and E. Chambilla-Mamani. 2010. Importance of dietary fiber, their functional properties in food and food industry. Rev. Invest. Cien. Technol. Aliment. 1: 1-14.

Mazzarella, L., D. Disalvatore, V. Bagnardi, D. G. Rotmensz, S. Caputo, G. Curigliano and P. G. Pelicci. 2013. Obesity increases the incidence of distant metastases in oestrogen receptor-negative human epidermal growth factor receptor 2-positive breast cancer patients. Eur. J. Cancer. 49: 3588-3597.

Mela, D. J. 2001. Determinants of food choice: Relationships with obesity and weight control. Obes. Res. 9: 249S-255S.

Melanson, K. J., T. J. Angelopoulos, V. T. Nguyen, M. Martini, L. Zukley, J. Lowndes, T. J. Dube, J. J. Fiutem, B. W. Yount and J. M. Rippe. 2006. Consumption of whole-grain cereals during weight loss: Effects on dietary quality dietary fiber, magnesium, vitamin B-6, and obesity. J. Am. Diet. Assoc. 106: 1380-1388.

Moyano, G., S. G. Sáyago-Ayerdi, C. Largo, V. Caz, M. Santamaria and M. Taberno. 2016. Potential use of dietary fibre from Hibiscus sabdariffa and Agave tequilana in obesity management. J. Funct.
Foods. 21: 1-9.

Müller, T. M., A. Müller, C. Yi, K. M. Habegger, C. W. Meyer, B. D. Gaylinn, B. Finan, K. Heppner, C. H. Trivedi, M. Bielohuby, W. Abplanalp, F. Meyer, C. L. Piechowski, J. Pratzka, K. Stemmer, J. Holland, J. Hembree, N. Bhardwaj, C. Raver, N. Ottaway, R. Krishna, R. Sah, F. R. Sallee, S. C. Stephen, S. Woods, D. Perez-Tilve, M. Bidlingmaier, M. O. Thorner, H. Krude, D. Smiley, R. DiMarchi, S. Hofmann, P. T. Pfluger, G. Kleinau, H. Biebermann and M. H. Tschöp. 2013. The orphan receptor Gpr83 regulates systemicenergy metabolism via ghrelin-dependent and ghrelin-independent mechanisms. Nat. Commun. 4: 1968.

Nakasato, M., N. Murakami, Y. Date, M. Kojima, H. Matsuo, K. Kangawa and S. Matsukara. 2000. A role for ghrelin in the central regulation of feeding. Nature. 409: 194-198.

Pereira, M. A. and D. S. Ludwig. 2001. Dietary fiber and body-weight regulation. Observations and mechanisms. Pediatr. Clin. North Am. 48: 969-980.

Polesel, J., A. Zucchetto, M. Montella, L. Dal Maso, A. Crispo, C. La Vecchia, D. Serraino, S. Franceschi and R. Talamini. 2009. The impact of obesity and diabetes mellitus on the risk of hepatocellular carcinoma. Ann. Oncol. 20: 353-357.

Preziosi, G., J. A. Oben and G. Fusai. 2014. Obesity and pancreatic cancer. Surg. Oncol. 23: 61-71.

Ramadas, A., M. Kandiah, H. Zarida, A. G. Yunus Gul and J. A. Faizal. 2009. Obesity and risk of colorectal adenomatous polyps: A case-control study in Kuala Lumpur hospital. Malays J. Nutr. 15: $1-10$.

Rendón-Huerta, J. A., B. Juárez-Flores, J. M. Pinos-Rodríguez, J. R. Aguirre-Rivera and R. E. Delgado-Portales. 2012. Effects of different sources of fructans on body weight, blood metabolites and fecal bacteria in normal and obese non-diabetic and diabetic rats. Plant Foods Hum. Nutr. 67: 64-70.

Renehan, A. G., M. Tyson, M. Egger, R. F. Heller and M. Zwahlen. 2008. Body-mass index and incidence of cancer: A systematic review and meta-analysis of prospective observational studies. Lancet. 371: 569-578.

Roberfroid, M. B. 2000. Prebiotics and probiotics: Are they functional foods? Am. J. Clin. Nutr. 71: 1682S-1687S.

Rodríguez, M. C., M. D. Parra, I. Marques-lopes, B. E. Martínez de Morentin, A. González and A. Martínez. 2005. Effects of two energy-restricted diets containing different fruit amounts on body weight loss and macronutrient oxidation. Plant Foods Hum. Nutr. 60: 219-224.

Sabaté, J. 2003. Nut consumption and body weight. Am. J. Clin. Nutr. 78: 647S-50S.

Salehifar, M. and V. Fadaei. 2011. Comparison of some functional properties and chemical constituents of dietary fibers of Iranian rice bran extracted by chemical and enzymatic methods. Afr. J. Biotechnol. 10: 18528-18531.

Schneeman, B. O. 1986. Physical and chemical properties, methods of analysis, and physiological effects. Food Technol. 40: 104-110.

Shimizu, M., T. Tanaka and H. Moriwaki. 2013. Obesity and hepatocellular carcinoma: Targeting obesity-related inflammation for chemoprevention of liver carcinogenesis. Semin. Immunopathol. 35: 191-202.

Silverman, D. T., C. A. Swanson, G. Gridley, S. Wacholder, R. S. Greenberg, L. M. Brown, R. B. Hayes, G. M. Swanson, J. B. Schoenberg, L. M. Pottern, A. G. Scwartz, J. F. Fraumeni and R. N. Hoover. 1998. Dietary and nutritional factors and pancreatic cancer: A case-control study based on direct interviwes. J. Natl. Cancer Inst. 90: 1710-1719. 
Simon, G. E., M. Von Korff, K. Saunders, D. Miglioretti, P. K. Crane, G. van Belle and B. Kessler. 2006. Association between obesity and pyshiatric disorders in the US population. Arch. Gen. Psychiatry. 63: 824-830.

Slavin, J. L. 2004. Dietary fiber and body weight. Nutrition. 21: 411-418.

Soret, R., J. P. Chevalier, G. De Coppet, P. Poupeau, J. P. Derkinderen and M. Segain. 2010. Short-chain fatty aciids regulate the enteric neurons and control gastrointestinal motility in rats. Gastroenterology. 138: 1772-1782.

Spiegelman, B. M. and J. S. Flier. 2001. Obesity and the regulation of energy balance. Cell. 104: 531-543.

Stanley, J. C., J. A. Lambadarios and E. A. Newsholme. 1986. Absence of effects of dietary wheat bran on the activities of some key enzymes of carbohydrate and lipid metabolism in mouse liver and adipose tissue. Br. J. Nutr. 55: 287-294.

Sun, B. and M. Karin. 2012. Obesity, inflammation, and liver cancer. J. Hepatol. 56: 704-713.

Swinburn, B. A., L. Caterson, J. C. Seidell and W. P. T. James. 2004. Diet, nutrition and the prevention of excess weight gain and obesity. Public Health Nutr. 7: 123-146.

Toffanin, S., S. L. Friedman and J. M. Llovet. 2010. Obesity, inflammatory signaling, and hepatocellular carcinoma - An enlarging link. Cancer Cell. 17: 115-117.

Tsigos, C., V. Hainerb, A. Basdevantc, N. Finerd, M. Friede, E. Mathus-Vliegenf, D. Micicg, M. Maislosh, G. Romani, Y. Schutzj, H. Toplakk and B. Zahorska-Markiewiczl. 2008. Management of obesity in adults: European clinical practice guidelines. Obes. Facts. 1: 106-116.

Udani, J. and B. B. Singh. 2007. Blocking carbohydrate absorption and weight loss: A clinical trial using a proprietary fractionated white bean extract. Altern. Ther. Health Med. 13: 32-37.

Urías-Silvas, J. E., P. D. Cani, E. Delmée, A. Neyrinck, M. G. López and N. M. Delzenne. 2008. Physiological effects of dietary fructans extracted from Agave tequilana Gto. And Dasylirion spp. Br. J. Nutr. 99: 254-261.

Wanders, A. J., J. J. G. van den Borne, C. de Graaf, T. Hulshof, M. C. Jonathan, M. Kristensen, M. Mars, H. A. Schols and E. J. M. Feskens. 2011. Effects of dietary fi011 on subjective appetite, energy intake and body weight: A systematic review of randomized controlled trials. Obes. Rev. 12: 724-739.

Wang, Z. Q., A. R. Zuberi, X. H. Zhang, J. Macgowan, J. Qin, X.
Ye, L. Son, Q. Wu, K. Lian and W. T. Cefalu. 2007. Effects of dietary fibers on weight gain, carbohydrate metabolism, and gastric ghrelin gene expression in mice fed a high-fat diet. Metabolism. 56: 1635-1642.

Weickert, M. O. and A. F. Pfeiffer. 2008. Metabolic effects of dietary fiber consumption and prevention of diabetes. J. Nutr. 138: 439-442.

Weir, G. C., S. Mojsov, G. K. Hendrick and J. F. Habener. 1989. Glucagonlike peptide 1 (7-36) actions on endocrine pancreas. Diabetes. 38: 338-342.

Wellman, N. S. and B. Friedberg. 2002. Causes and consequences of adult obesity: Health, social and economic impacts in the United States. Asia Pac. J. Clin. Nutr. 11: S705-S709.

World Cancer Research Fund International (WCRF International). Available from: http://www.wcrf.org/cancer_statistics/data specific_cancers/colorectal_cancer_statistics.php. [Last accesed on 2014 Jun 30].

World Health Organization, (WHO). 2016. Obesity and overweight. Available from: http://www.who.int/gho/ncd/risk_factors/ overweight_text/en/. [Last accessed on 2015 Jul 13].

World Health Organization. 2012. Depression. Fact Sheet No. 369. WHO, Geneva.

Wright, S. M. and L. J. Aronne. 2012. Causes of obesity. Abdom. Imaging. 37: 730-732.

Xu, Q., D. Anderson and J. Lurie-Beck. 2011. The relationship between abdominal obesity and depression in the general population: A systematic review and meta-analysis. Obes. Res. Clin. Pract. 5: e267-e278.

Zhao, G., E. S. Ford, C. Li, J. Tsai, S. Dhingra and L. S. Balluz. 2011. Waist circumference, abdominal obesity, and depression among overweight and obese US. Adults: National health and nutrition examination survey 2005-2006. BMC Psychiatry. 11: 130.

Zigman, J. M., Y. Nakano, R. Coppari, N. Balthasar, J. N. Marcus, C. E. Lee, Jones, J. E., Deysher, E., A. R. Waxman, R. D. White, T. D. Williams, J. J. Lachey, R. J. Seeley, B. B. Lowell and J. K. Elmquist. 2005. Mice lacking ghrelin receptors resist the development of diet-induced obesity. J. Clin. Invest. 115: 3564-3572.

Zimmet, P. and C. R. Thomas. 2003. Genotype, obesity and cardiovascular disease has technical and social advancement outstripped evolution? J. Int. Med. 254: 114-125. 